\title{
A review of the strategic planning process in the Hong Kong Police Force
}

\author{
Hoi-yan Cheung \\ Hong Kong Police Force, and \\ Eddie $\mathrm{Yu}$ \\ Hong Kong Management Association
}

\begin{abstract}
Purpose - The purpose of this paper is to review the strategic planning process of the Hong Kong Police Force (the Force) and its outcomes for the planning cycle of 2019-2021.

Design/methodology/approach - Based on an insider's perspective drawn from documentation, internal reports and field observation, this study is an analysis of the five-step strategic planning process of the Force as a case study over the two-year period by using the 3-H (Heart-Head-Hand) framework and futures studies.

Findings - This study demonstrates the Force's strategic management in practice. The 3-H framework and the Six Pillars Foresight Process are found to be useful tools in strategic planning. When the Heart, Head and Hand elements are developed and integrated as a mindset during the process, they help theorise the practice and experience of police officers towards a holistic and effective strategic management. Coupled with the foresight process, the Force will be more agile and outward focused in the Volatile, Uncertain, Complex and Ambiguous (VUCA) world.

Originality/value - This is the first study to apply the 3-H framework and futures thinking in analysing the process in a police organisation in Hong Kong. While strategic planning is an important process to set directions for an organisation to move forward, this study describes the process in terms of relevant practice and theoretical concepts. It is hoped that such experience can serve as reference for practitioners in other government departments and police organisations.
\end{abstract}

Keywords Strategic planning, 3-H framework, Six Pillars Foresight Process, Futures studies,

Hong Kong Police Force

Paper type Research paper

\section{Introduction}

Strategic planning is considered to be an important process in large organisations, both public and private. It has become more prominent on the public organisations' agenda due to the new public management reforms, but literature reveals that there are very few studies exploring how public organisations apply strategic management in practice and what tools are being used (Höglund et al., 2018). The police organisation operates for the benefit of the whole society and is therefore having a specific mission to ensure a high level of performance of statutory tasks by complying with existing legislation and protecting citizens from crime (Dworzecki and Hryszkiewicz, 2016). It is of utmost importance for police organisations to adopt strategic planning in order to set strategic directions to move forward, achieve a shared vision and shape the future.

As a pre-emptive introduction to the concept of futures thinking, it is important to ask the management of an organisation to respond to a series of questions relating to the most

(C) Hoi-yan Cheung and Eddie Yu. Published in Public Administration and Policy. Published by Emerald Publishing Limited. This article is published under the Creative Commons Attribution (CC BY 4.0) licence. Anyone may reproduce, distribute, translate and create derivative works of this article (for both commercial and non-commercial purposes), subject to full attribution to the original publication and authors. The full terms of this licence may be seen at http://creativecommons.org/licences/by/4.0/ legalcode

\section{HKPAA}

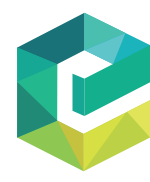

Public Administration and Policy Vol. 23 No. 3, 2020 Emerald Publing-258 1727-2645 DOI 10.1108/PAP-06-2020-0027 
PAP

23,3

\section{6}

challenging aspects of today's world and how they envisage this challenge in the future. Since 2006, the Hong Kong Police Force (the Force) has introduced the Strategic Planning Process (the process), which is a five-step approach to formulate the Strategic Directions (SDs) and Strategic Action Plan (SAP) for the next three years. The five steps include environmental scan, identifying issues, setting directions, formulating options and developing plan (Hong Kong Police Force, 2020).

\section{Research methodology}

Given the popularity of strategic planning in the public sector in the past decades, there has been little research on this topic (Zhao et al., 2008). This paper aims at applying the 3-H (HeartHead-Hand) framework (Yu, 2019) to review and reflect on the Strategic Planning Process and its output conducted by the Force between June 2017 and June 2019. It is one of the first attempts to examine and reflect on the strengths and weaknesses towards a more holistic approach to improve the Force's strategic management process.

The first author provided an insider's perspective by conducting content analysis of transcripts created from 28 interviews with targeted senior officers, internal reports and key documents including the Legatum Prosperity Index 2019 (Legatum Institute, 2019), the Environmental Scan Report 2018 (Hong Kong Police Force, 2018b), the Management Information Pack (Hong Kong Police Force, 2018c), the Strategic Directions 2019-2021 (Hong Kong Police Force, 2019a) and Strategic Action Plan (Hong Kong Police Force, 2019b). Each step of the process was observed through the lens of the 3-H framework and futures studies. The content analysis, field observations and the output of the process were synthesised to produce the findings which were found to be meaningful in the relevant management theory. This paper also examines how this process can be improved with enhanced effectiveness and efficiency to address the compelling needs of future policing, especially when the operating environment is increasingly complex, politicised and hostile.

By adopting a case study approach, this study has made use of the first author's unique position as the driver of the whole strategic planning process with a view to generating greater insights into this area of inquiry. When compared to other methodology in conducting research, Harrison et al. (2017) stated the strengths of case study designs being able to assist researchers to address complex issues through exploration, explanation, description, evaluation, and theorisation in context. Through conducting case study, researchers would be able to have an in-depth understanding of behaviours of the protagonists, planning processes, practices and relationships through the research outcomes in context. The efficacy of case study approach being a powerful form of qualitative research had been strengthened through application of and sound debate about the value, validity, and capability of case study research (Harrison et al., 2017).

\section{The Hong Kong Police Force in context}

The Force is the largest government department in Hong Kong, which has a strength of 29,268 disciplined staff as at 30 April 2018 (Hong Kong Police Force, 2018a). The Force is commanded by the Commissioner of Police (CP) who is assisted by two Deputy Commissioners (DCP) as in June 2019. The Force Headquarters is made up of five departments: Operations (Department A); Crime and Security (Department B); Personnel and Training (Department C); Management Services (Department D); and Finance, Administration and Planning (Department E). Each department is headed by a Senior Assistant Commissioner of Police (SACP). The DCPs and SACPs form the Senior Directorate Group (SDG). Under the SACPs, there are 18 Assistant Commissioners of Police (ACP) including two Auxiliary Police Commanders and two civilians. These 28 key officers are referred as Commissioner Rank Officers (CRO) and form the Force senior management cadre 
(Hong Kong Police Force, 2018a). The first author of this paper was the Head of Efficiency Studies Bureau who was responsible for driving the Force's strategic planning process from 2017 to 2019.

The Force's strategic planning is an essential tool to drive continuous quality service delivery and organisational excellence long into the future (Booth, 2018). It refers to the process by which an organisation determines and articulates its strategy and how it intends to achieve it. Literature reveals that strategic planning has become increasingly popular in the public sector as standard practice on the belief that strategic planning can lead to better organisation performance. However, there has been insufficient research on public-sector strategic planning and its connection with implementation and performance (Bryson et al., 2017).

\section{Five-step approach in strategic planning}

The process was first introduced in the Force in 2006 and the first set of SDs and SAP were published in 2008. Both have a 3-year life cycle and the current process commenced in June 2017 to formulate the SDs and SAP 2019-2021. The process consists of five distinct stages (Figure 1). The process guides the Force through a deliberate, long-term view of development and aims at identifying areas for improvement to meet current needs and any additional capabilities required to face anticipated and emerging challenges.

The process begins with a detailed environmental scan of worldwide and local trends, the Force's internal developments, and advances in the fields of international policing and law enforcement. Following comprehensive discussions and reviews through CRO interviews and scenario planning, Senior Management prioritises the strategic issues and determines the SDs for the Force. In support of the SDs, options are carefully considered, and the SAP is formulated in the form of a coordinated set of Key Initiatives.

The Force's Environmental Scan Report 2018 (the Report) consists of three parts. Part one presents new areas of development in the world under the PESTEL model representing political, economics, society and demographics, technology and science, environment and health as well as legal. Part two identifies the emerging challenges and issues from across the

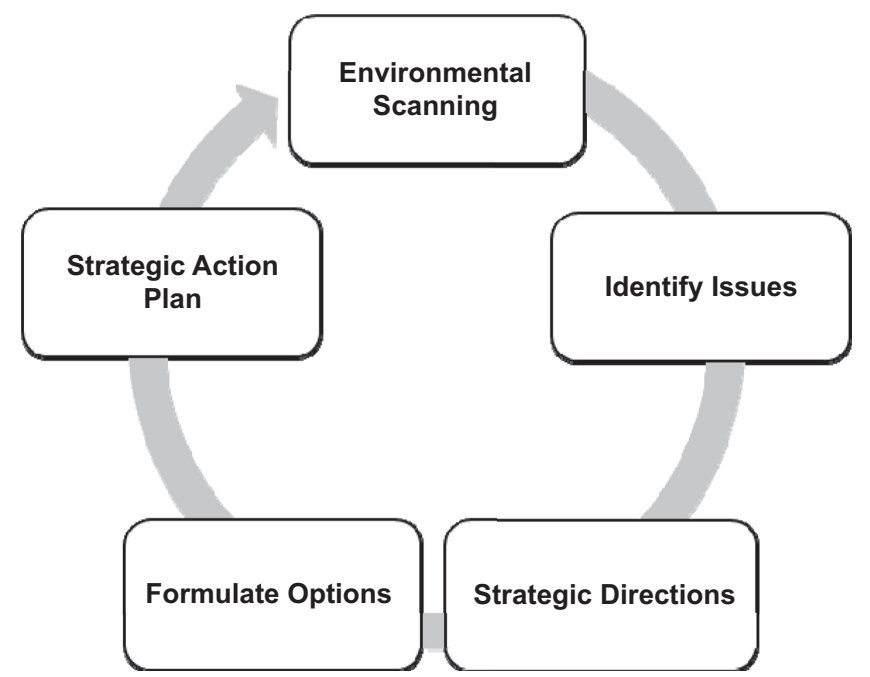

Source: By first author (2020)
Strategic planning in Hong Kong Police Force
Figure 1.

The Five-step approach of strategic planning 
PAP

23,3

248

Force. Part three highlights contemporary initiatives in international policing. The Report was published in January 2018 (Hong Kong Police Force, 2018b).

Between February and May 2018, individual interviews with the 28 CROs were conducted to identify strategic issues that would impact the Force in the next three to five years. The interviews were recorded as transcripts and consolidated into a Management Information Pack (Hong Kong Police Force, 2018c) which included strategic issues, enterprise risk management information, future scenarios and survey results. In this cycle, the Enterprise Risk Management process and scenario planning were newly added. The ISO 31000:2009 framework of Risk Management was adopted to manage risk effectively and allow an organisation to perform well through identification of anticipated threats and allocation of resources for risk treatment. This task was carried out by a team of officers who were either academically qualified or having experience in the field of risk management. The risk assessment results were included in the Management Information Pack. Scenario planning, sometimes referred as "scenario and contingency planning", is a useful tool for organisations to ponder the future in a structured way. Due to the rapid changing environment, scenario planning was conducted and four plausible scenarios in 2028 which presented significant impacts on future policing were derived and discussed among CROs at the first CROs Strategic Planning Conference. Three surveys were conducted by the Force in January and February 2018, namely the Police Service Satisfaction Survey, the Public Opinion Survey as well as the Staff Opinion Survey. The Management Information Pack was produced one month before the first CROs Strategic Planning Conference in August 2018, for internal consumption. During this conference, all CROs discussed the most compelling strategic issues and presented their findings at the end of the conference.

After the first CROs Strategic Planning Conference, insights were incorporated in an internal report as a reference for the formulation of the SDs. As a result of the conference held in September 2018, three new SDs were set by the CP and Senior Directorate officers aiming to steer the Force in facing emerging challenges and rising public expectations in the next three years. A second CROs Strategic Planning Conference was held in November 2018, to solicit input from the ACPs with a view to finalising the objectives of each SD. The Strategic Directions 2019-2021 (Hong Kong Police Force, 2019a) was officially published and a briefing to all senior commanders was held in February 2019. Between January and June 2019, a series of meetings by the Senior Directorate officers was held to formulate options (step four) for the SAP 2019-2021 (step five), which was finalised with an online version (Hong Kong Police Force, 2019b).

\section{Literature review}

Over the past decades, there have been a variety of strategic planning definitions. Strategic planning can be defined as an upper management-initiated process aiming to set specific goals for an organisation and to identify possible steps for success through implementing planned changes within a span of two to five years (Zhao et al., 2008). Strategic planning aims to shift traditional focus on existing challenges towards the exploration and understanding of possible futures. Literature reveals that strategic planning in police departments has transformed from the traditional reactive orientation to a more proactive focus with a view to responding to the need for adapting to a changing operating environment (Zhao et al., 2008).

As law enforcement was originally organised on a territorial basis, this strong territorial approach partially explains why police forces nowadays are less properly suited for the borderless and high-paced crime landscape. Another significant theme is the recognition of the shift in crime levels from predominantly traditional areas such as burglary, robbery, and delinquency being replaced by technology-enabled crime (Dworzecki and Hryszkiewicz, 2016). Consequently, the need for adaptive, dynamic and flexible law enforcement responses to crime is particularly important. 
Managing a large police organisation is extremely challenging, in particular in this Volatile, Uncertain, Complex and Ambiguous (VUCA) world (Gupta and Gupta, 2018). Given the popularity of strategic planning in many western countries, such as the US and the UK, academics still question its usefulness and doubt has been expressed over the effectiveness of strategic planning in police forces (Elliott et al., 2019; Zhao et al., 2008). Therefore, this research attempts to fill this gap by examining the strategic planning process in the Force and presenting findings to inform knowledge and future practice in this field.

\section{3-H Framework}

The question of what constitutes a good management is always asked. According to $\mathrm{Yu}$ (2019), "a good management is an art and science of getting things done effectively and efficiently through people and other required resources guided by 3-H framework." 3-H framework ( $\mathrm{Yu}$, 2019 ) is a mindset for managing people and organisational issues in a holistic way. Each $\mathrm{H}$ domain of the $3 \mathrm{H}$ framework has an array of established theoretical groundworks rooted from well-established literature in respective fields. For instance, transformational leadership, which forms a key part of H1 Heart domain, can be represented by the seminal works of Bass (1995; 2010), strategic planning for H2 Head domain by Mintzberg (1987; 1994) and Senge (1990; 2003), competence H3 Hand domain by Barney (1996; 2001).

Instead of separating the domains into three categories, Nicholls (1994) focused on creating a construct of leadership with three perspectives: inspirational, strategic and supervisory. Inspirational leadership focuses on people's personal beliefs while the other two focus on the organisation and the operation. On the contrary, Yu (2019) by categorising established literature of each $\mathrm{H}$ domain as illustrated above and represented by metaphoric expressions of "Heart, Head and Hand" as necessary factors and together with an integration strategy, as sufficient condition, to synergistically complement all three $\mathrm{H}$ domains together to create a holistic approach to manage the entire strategic planning process and to achieve intended strategic goals. Such relationship can be simply expressed by the following formula (Yu, 1997):

$$
\mathrm{OP}=\mathrm{f}(\mathrm{H} 1 \mathrm{cH} 2 \mathrm{cH} 3)
$$

- $\mathrm{OP}=$ Organisational Performance

- $\mathrm{c}=$ Complement

- $\mathrm{H1}=$ Heart (leading, motivating and engaging people ability)

- $\mathrm{H} 2$ = Head (strategic, organisational, cognitive ability)

- $\mathrm{H} 3$ = Hand (operational/functional ability)

$\mathrm{H} 1, \mathrm{H} 2$ and $\mathrm{H} 3$ are necessary factors for effective organisational performance. Level of cohesive complement and integration of all 3H domains, as sufficient condition, shall determine the level of efficiency and effectiveness of the organisation's long-term performance.

The process of the Force is analysed through the lens of 3-H framework in the next section.

(a) The Heart-oriented approach

Heart-oriented dimension means caring about motivational and human aspects in management practices aiming to motivate employees to commit in achieving organisational goals. It is the most challenging part among all three dimensions because dealing with people and changing their attitudes and behaviour is the most difficult job. The Heart dimension has to be tackled well before the management pushes through the implementation of any new initiatives or changes (Yu, 2019).

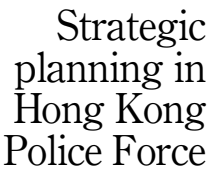


PAP

23,3

Motivation represents a key part of Heart domain. In the past century, motivation has been studied widely by researchers who explored motivation through constructs such as needs satisfaction. These perspectives provide a different understanding of the implications for comprehending motivation in the workplace (McRee, 2018). The five basic human needs including physiological, safety, love, esteem and self-actualisation form the foundation of seminal work on human motivation (Maslow, 1943). People tend to seek a "higher" motivation once a basic need is satisfied. Maslow (1943) further elaborates that individuals who become self-sufficient from their physical and social environment will attain self-actualisation drawing on latent resources within. McClelland (2010) developed human motivation theory in the 1960s, referred to as learned needs theory. He stated that this theory included need for achievement, need for affiliation and need for power, that were translated into motivational drivers driving behaviour. Ryan and Deci (2008) identified three psychological needs as basic and universal to all people: autonomy, competence and relatedness. If these three psychological needs were not satisfied, self-determination theory pointed to the social environment and then to the developmental environment to understand which need had been or was being frustrated.

Apart from motivation theories, a Heart domain also includes other key constructs such as leadership and values. Two empirical studies on the police organisations evidenced that perceived supporting leaders and conducive core values had significant impacts on the motivation and work engagement with the police officers (Basinska and Dåderman, 2019; Gillet et al., 2013). It is envisaged that motivated and engaged officers are more willing to make extra effort - 'want to' get the job done well (Yu, 2019). However, even the entire organisation is motivated and enthusiastic in supporting its initiatives, if strategies are poorly planned (weak in $\mathrm{H} 2 \mathrm{Head}$ ), the organisation will not be able to achieve its strategic goals. Hence, we need to examine the integrity of the Head (H2).

(b) The Head-oriented approach

The metaphor of 'Head' means the mind of strategists, strategic planners and commanders, and they have visionary, strong planning, organising and control expertise. The framework believes strategy planning is what Mintzberg (1987) advocates: a crafting rather than a mechanical or engineering process. The strategists are required to possess strategic thinking, planning, creative and analytical skills. Other qualities include mindfulness of developing a competence that is adaptable to a dynamic environment and is of critical importance to the sustainability of that competence. Equally important is about developing an organisational process, which is conducive to synthesising the organisation's human, technical, physical and financial resources together to create the organisation's core competence (Yu, 2019).

To complement the Head-oriented approach, the "Six Pillars Approach" as a conceptual framework of futures studies, elaborated below, is a useful tool to reinforce the strategic thinking of the Head-oriented approach. The "Six Pillars Approach of Futures Studies" (Inayatullah, 2008) can be used as a theory of futures thinking or as a tool in a futures workshop. The six pillars (MATDCT) are as follows:

i. mapping futures

ii. anticipating futures

iii. timing

iv. deepening futures

v. creating alternative futures

vi. transforming futures 
Head-oriented implementation concerns the formulation of strategy from viewing the world in new ways. Strategy also starts with an ability to think in new and unconventional ways (Hamel and Breen, 2007). Head approach manifests outcomes typically evidenced by the organisation's generic competitive advantages of CRIAQES (Yu, 2019):

- Citizen responsiveness - to their needs and preferences;

- Innovation - in managing operation process and offering new services with new IT and AI technologies;

- Agility - flexibility and dexterity in deployment to cope with odd incidents;

- Quality - delivering citizen expected standard of service and meeting performance pledges;

- Efficiency - yielding cost effectiveness in all operations;

- Speed - in response to, e.g., 999 calls and other emergencies.

In practice, Hand (H3) domain facilitates CRIAQES in service delivery and implementing the H2-organised programmes and activities. When the 'soft' side of H1 Heart factors are duly considered in the strategic planning process, the workforce will be more motivated to implement the strategic action plan. As the entire operation system and H3 Hand competence issues have been well addressed and organised, the Force will be more likely to efficiently achieve operational goals. On the other hand, even a sound strategic plan is developed, if the H1 Heart dimension issues have not been well dealt with, the police, especially the rank-andfile police officers may not be committed to achieving its goals. If H3 Hand competence is lacking, implementation of the strategy will be slow and erroneous. That leads us to discuss the final $\mathrm{H}$ - Hand-oriented perspective of the 3-H framework.

(c) The Hand-oriented approach

The metaphor of 'Hand' means the competences for police officers, such as crime investigation, crowd control, handling emergencies and knowledge of criminal laws. No matter how great the strategy or plan is, all organisations have to rely on the frontline workforce to implement programmes and plans. The core function of the Hand domain is to implement the Force's strategic and tactical plans to achieve its respective strategic goals. Guiding by Barney's (1996) resource-based theory, the Force's management has to ensure the resources, especially its police officers, are well developed and refined for building a stronger Force.

\section{Futures studies}

Futures studies is the systematic study of 'possible, probable and preferable futures' (Inayatullah, 2007). Futures studies has become more structured and no longer rely solely upon external forces in predicting the future such as astrology and prophecy. According to Inayatullah (2007), the planning departments and organisations around the world have started to adopt futures studies in their planning processes. Planning tends to attempt to control and close the future, while on the contrary, futures studies seeks to shape and open up the future so that more alternatives can be developed (Inayatullah, 2007). Ultimately, the objectives and intention behind the futures studies are not only academic but about transforming or shaping the future in order to build a more sustainable world. Research suggests that human is extremely interested in what will happen to them, but they generally rely heavily on histories or past experience, regardless of success or failure, to decide their action in the future (Inayatullah, 2007). This is what Marshall McLuhan suggested decades ago, "the future with a rear-view mirror" (Carmody, 2011). 
PAP

23,3

One of the distinctive characteristics of futures studies is to investigate the 'range' of futures. The goal is not only to explore new organisational directions but also to challenge and clarify current management decisions. Although the future remains unknown to us, we can distinguish probable and preferred futures and determine what we desire (Inayatullah, 2007). This is particularly important to the process of strategic planning because during the planning process, we not only want to have a shared vision on what we want our organisation to be, but also to shape the future to our favour. Futures studies is vision-oriented which gives individuals and organisations a possible vision of the future world. It is hoped that every individual will be inspired to focus on the longer term instead of the short term in order to achieve the greater good. In the end, it seeks to help align individual goals with organisational or institutional goals (Inayatullah, 2007).

\section{Analysis of the strategic planning process}

With reference to the 3-H framework and futures studies theories, this paper aims to review and analyse through the lens of the 3 -H perspectives in the Force's strategic planning process between June 2017 and June 2019. To recap the five-step approach, the process includes environmental scan, identify issues, set directions, formulate options and develop plans (Hong Kong Police Force, 2020). The effectiveness of the process is examined based on content analysis of public documents, internal reports, interview transcripts and field observation.

In step one, Heart domain calls for transformational leadership for the commanders to identify needed change, creating a vision to guide the change through engagement with all levels of the Force to execute the change and to meet the challenges emerging from the increasingly complex and hostile environments (Bass, 1995). In practice, the senior management allowed the planning team to have full autonomy on compiling and designing the Report, which represented the buy-in process suggested by Heart (H1) initiative. The Report had a brand-new format based on new research. All topics were presented using compelling info-graphics and thought-provoking questions. It was designed to inspire strategic thinking through the posing of poignant questions and the presentation of pertinent data across the spectrum of factors that constituted the future operating environment. All commanders were expected not only to identify the issues relating to the challenges and opportunities the Force would face in the near future, but also attempted to go beyond the obvious, to fully embrace an uncertain future in the search for solutions, directions and innovations (Hong Kong Police Force, 2018b). The Report was a tool to identify the challenges of the future so that commanders might take steps to prepare the organisation. The new design and the selection of topics with future focus were well received. The entire process is characterised as what Mintzberg (1987) suggests a crafting rather than formulating nature of activities. In summary, Head (H2) guides environmental scanning on identifying the key drivers in the Force's task environment which were analysed to ascertain material impacts to the Force, as these have to be addressed in subsequent steps.

During step two, all 28 CROs were interviewed individually by the first author and invited to identify strategic issues impacting the Force in the next three to five years. The length of the interviews ranged from forty-five minutes to one and a half hour. Their responses were recorded as transcripts and consolidated anonymously into the Management Information Pack (Hong Kong Police Force, 2018c). Their commitment and devotion were fully reflected in their input and contribution in the interview records. Their full participation and invaluable comments demonstrated their leadership and people-oriented (H1) mindset.

The two CROs Strategic Planning and the CP \& SDG Strategic Review Conferences formed the third step of the process. All CROs actively participated in the discussion and unpacked the strategic issues identified. A sense of collective ownership was demonstrated during the conferences and they had a shared vision and strategic goals. These were 
important elements to communicate their vision to their staff and gain buy-in in implementing their formation action plans subsequently. Heart (H1) purpose-sensing is important in the buy-in process for reception to the plan and subsequent smooth implementation. As Carton (2018) alludes, people are often motivated to achieve organisational goals if they feel purposeful in carrying out their duties. Such effect is applicable to management and frontline staff.

During step four (formulating options) and step five (strategic action plan), the senior management held a series of meetings from January to June 2019 to formulate options under each SD and finalise the SAP by using the Six Pillars Foresight Process under Head (H2) dimension to map the futures of the organisation. "Futures Triangle" and "Backcasting" were adopted during the discussion of the strategic options in the meetings. "Futures Triangle" (Inayatullah, 2007) on policing was developed based on the operating research question or a strategic issue taking into account of four areas: i) the futures triangle concept; ii) images of the future; iii) quantitative pushes of the present; and iv) weights of history. These allow senior management to think strategically in formulating options under each SD and to develop new and unconventional ways in drawing up the strategic action plan.

The implementation of the Heart and Head-oriented approaches during the first three steps of the process were considered to be successful based on field observation and content analyses. The publication of the SDs 2019-2021 and formulation of SAP (Hong Kong Police Force, 2019a; 2019b) represented the outputs of the process. The new SDs aimed to focus the Force's efforts in three key areas to ensure that Hong Kong remains one of the safest and most stable societies in the world which is the Force Vision. In the last two steps of the process, the Six Pillars Foresight Process under Head (H2) dimension and the tools of "Futures triangle" and "Backcasting" were used to secure success in formulating options (step four) and the SAP (step five). It is important to ensure that all officers share the organisation vision, mission and values. The objectives of maintaining a high standard of professionalism, personal conduct and integrity at all times were included in the strategic vision under the new SDs. Officers of all ranks, especially frontline police officers, who are required to carry out the action plans on a daily basis must be motivated (Heart-H1 dimension). The overall plans and activities have to be cascaded down to the frontline effectively and the officers are equipped with new occupational skills and competences (Hand-H3 dimension). In order to adapt to emerging challenges in the next three years, all levels of the Force's members must be trained with new skills and capabilities for policing in the digital era (Hong Kong Police Force, 2019a). Apparently, the moment of truth only occurs when the $3 \mathrm{H}$ necessary factors have been effectively integrated to deliver a holistic approach to embrace the five-step strategic planning process as depicted in Figure 2 below.

\section{Discussion}

This paper aims to review how the Force strategic planning process can be improved with enhanced effectiveness and efficiency to address the compelling needs of future policing. Through synthesising content analyses, field observations and the output of the process, the authors produced the findings which were found to be meaningful in the relevant management theory. In the contemporary world, crimes have become increasingly transnational and empowered new roles in society due to globalisation. The use of novel technologies has become popular among criminal groups. Technologies continue to have positive and negative impact in our world in a faster pace.

Competent strategists are required to adopt a holistic mindset to envision the business and social trends, identify opportunities, foresee challenges and threats as well as to effectively respond faster than others $(\mathrm{Yu}, 2019)$. Without foresight, our strategy and innovation will only, at best, be based on a narrow understanding of the future. At worst, they are based on assumptions only informed by the past (Woodling and Jones, 2018). Given the pace of change

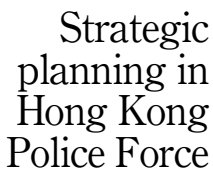

253 


\section{PAP}

23,3

\section{4}

Figure 2 .

An integrated $3 \mathrm{H}$ approach driving the Force's strategic management process

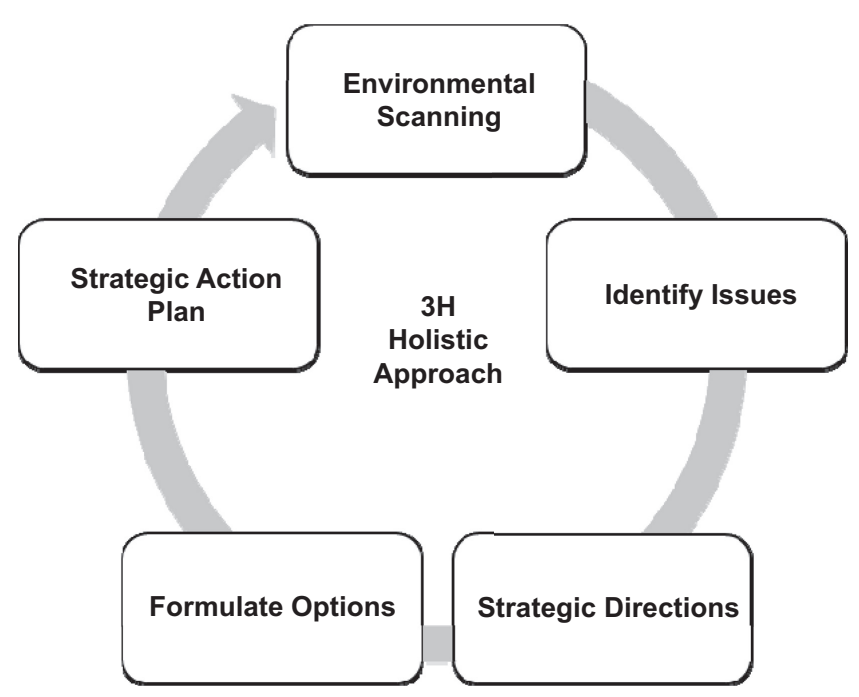

Source: By authors (2020)

and complexity of the operating environment, it is found that strategic planning should be driven by a new thinking process rather than a conventional or mechanical way. Like most organisations, the Force adopts a routinised and structured process that the component of creative strategising is yet to be developed (Heracleous and Jacobs, 2011). In other words, a static strategy fixed for a set period of term will become increasingly ineffective. A strategic plan should be a living and breathing document that can respond to the need of an organisation constantly, rather than a 'set-and-forget' instrument (Paton, 2018).

Meanwhile, digitalisation reproduces or even worsens inequality in the global community as a result of unequal access to technology and data. While some groups benefit from advancement in technology, others remain left out. Law enforcement agencies worldwide are facing increased gap in policing capabilities among countries and this results in more complex global security challenges (Dworzecki and Hryszkiewicz, 2016). In view of the challenges arising from the applications of artificial intelligence and robotics, it is a common consensus that law enforcement must continuously respond to changes and develop more innovative skillsets and technological solutions to tackle emerging crimes (Hong Kong Police Force, 2019a). These skillsets and capability building within an organisation become the focus of the Hand-oriented approach. Only by continuously seeking improvements in a changing environment can a police organisation stay ahead of the wave. As a result, it has been a good practice for global law enforcement agencies to start looking into how policing can leverage on technology in the digital age.

Technologies will maximise the time frontline police officers spend on delivering their core services and meeting the needs of the community. It is of utmost importance that police forces look into technological solutions that will enable public access to service and improve operational efficiency and effectiveness (Hong Kong Police Force, 2019a). Police may even deter criminal activities through proactive actions driven by data analytics and evidencebased policing strategies. The ultimate aim is to deliver a faster and more focused response through real-time information sharing and effective decision-making. Among these key drivers of strategic changes from the task environment, our findings reveal that the impacts from technologies to the Force operations have not been adequately assessed with $\mathrm{H} 2$ 
perspective. Consequently, it may affect the development of CRIAQES competence at the $\mathrm{H} 3$ level, especially on agility and speed in collecting, analysing intelligence and service delivery.

There are a lot of possibilities, disruptions and changes in the next ten to thirty years. Since the existing and most challenging policing issues are mainly in an international context, instead of focusing on solutions at national or regional level, there has been a strong demand for interactive dialogues among law enforcement agencies. It is generally agreed that co-creation and proactive partnership with different law enforcement agencies, academia and private sectors becomes the focus of future policing strategies in addressing the current and emerging threats in the global operating environment (Inayatullah, 2018). These rely on the Heart-oriented approach adopted by different levels of staff to be committed and determined in making extra effort. To get true involvement of staff, a vertical slice right down through the organisation is necessary so that this consultation becomes a powerful aid for senior leadership to understand the daily challenges of the frontline staff and to inform the strategy in the process (Paton, 2018). Under the police context, in order to allow police officers more flexibility in executing their duties, real-time mobile access to all required information and the capability for remote briefings, digital devices and dynamic scheduling technology are amongst the top priority in enabling the efficient use of an officer's time and creating a more flexible working environment (Hong Kong Police Force, 2018b). This may also attract and retain the new generation who are more 'tech-savvy' and innovative in their ways of thinking.

While this study makes it possible to review and reflect on the Force's strategic planning process through the lens of 3-H framework and futures studies, it does not cover the other two main processes in Force's strategic management, namely implementation and review. As a result, the Hand-oriented approach referring to new skillsets and competences in order to solve future problems ( $\mathrm{Yu}, 2019)$ is not fully applied in this study. One way of building on this research might be to extend it to cover the whole Force's strategic management and more research is needed to generate understanding of how frontline officers perceive the Force strategic management through empirical studies. According to Heracleous and Jacobs (2011), the component of creative strategizing is yet to be developed in most organisations, which can be a direction for future research. Strategic planning is how the people in an organisation make sense of where it wants to go and how it is going to get there (Booth, 2018). Whether the Force can maintain the organisational agility and legitimacy has become the most challenging question to be answered.

\section{Conclusion}

Having reviewed years of design, key documents and the analysis of the strategic planning process experience with 3-H framework, our findings reveal the following key lessons. First, top management's genuine commitment and support during the entire process is vital to the success of strategic management. When people believe that their leaders mean business and the leaders walk the talk, subordinates would seriously follow. Second, an effective heart-toheart communication, which indoctrinates purposeful cause helps the buy-in process as it will yield people's 'want to' commitment to achieve the strategic goals. Third, creating a 3-H conducive culture is important to support effective implementation of the strategic plan. Fourth, trust bonding will glue each $\mathrm{H}$ domain of the framework together to boost team spirit among different divisions within the police organisation. Last but not the least, synergistic alignment among 3-H domains to create a holistic approach to drive the strategic planning process is crucial to an effective strategic management in the Force.

In conclusion, this study has thoroughly reviewed the Force's strategic planning process. The authors attempt to theorise the existing strategic planning practice with the 
3-H framework - strategic planning with Head-oriented foresight process with the elements of futures studies, strategy to be executed with Hand-oriented competence approach by Heart-driven highly committed Force. We posit a holistic strategic planning and execution approach is the way to maintain Hong Kong as a safe and stable society amidst the VUCA world. The lessons drawn from this review created important positive impacts to the future strategic management for the Force - we know better how to achieve intended strategic goals and we can explain why and how we do it with relevant theories.

\section{References}

Barney, J.B. (1996), “The resource-based theory of the firm”, Organization Science, Vol. 7 No. 5, pp. 469-592.

Barney, J.B. (2001), "Resource-based theories of competitive advantage: a ten-year retrospective on the resource-based view", Journal of Management, Vol. 27 No. 6, pp. 643-650.

Basinska, B.A. and Dåderman, A.M. (2019), "Work values of police officers and their relationship with job burnout and work engagement", Frontiers in Psychology, Vol. 10 No. 442, pp. 1-13.

Bass, B.M. (1995), "Theory of transformational leadership redux", The Leadership Quarterly, Vol. 6 No. 4, pp. $463-478$.

Bass, B.M. (2010), "Two decades of research and development in transformational leadership", European Journal of Work and Organizational Psychology, Vol. 8 No. 1, pp. 9-32.

Booth, D.M. (2018), "Strategy for the strategists", Strategy Magazine, Vol. 1, pp. 19-22.

Bryson, J.M., Edwards, L.H. and Van Slyke, D.M. (2017), "Getting strategic about strategic planning research”, Public Management Review, Vol. 20 No. 3, pp. 317-339.

Carmody, T. (2011), "March backwards into the future - Marshall McLuhan's century", Wired, 21 July, available at: https://www.wired.com/2011/07/march-backwards-into-the-future-marshallmcluhans-century/ (accessed 31 August 2020).

Carton, A.M. (2018), "I'm not mopping the floors, I'm putting a man on the moon': how NASA leaders enhanced the meaningfulness of work by changing the meaning of work", Administrative Science Quarterly, Vol. 63 No. 2, pp. 323-369.

Dworzecki, J. and Hryszkiewicz, D. (2016), "Strategic management within the realms of the police related organisation", Science and Military Journal, Vol. 11 No. 2, pp. 48-56.

Elliott, G., Day, M. and Lichtenstein, S. (2019), "Strategic planning activity, middle manager divergent thinking, external stakeholder salience, and organizational performance: a study of English and Welsh police forces", Public Management Review, Vol. 21 No. 7, pp. 1-22.

Gillet, N., Huart, I., Colombat, P. and Fouquereau, E. (2013), "Perceived organizational support, motivation, and engagement among police officers", Professional Psychology, Research and Practice, Vol. 44 No. 1, pp. 46-55.

Gupta, D. and Gupta, V. (2018), "Effective policing in a VUCA environment: lessons from a dark network", in Dhir, S. and Sushil, S. (Eds.), Flexible Strategies in VUCA Markets, Springer, Singapore, pp. 89-111.

Hamel, G. and Breen, B. (2007), The Future of Management, Harvard Business Review Press, Boston, MA.

Harrison, H., Birks, M., Franklin, R. and Mills, J. (2017), "Case study research: foundations and methodological orientations", Forum: Qualitative Social Research, Vol. 18 No. 1, pp. 1-17.

Heracleous, L. and Jacobs, C.D. (2011), Crafting Strategy: Embodied Metaphors in Practice, Cambridge University Press, Cambridge.

Höglund, L., Holmgren, M., Martensson, M. and Svardsten, F. (2018), "Strategic management in the public sector: how tools enable and constrain strategy-making", International Public Management Journal, Vol. 21 No. 5, pp. 822-849. 
Hong Kong Police Force (2018a), "Hong Kong fact sheet - the Police”, available at: https://www.police. gov.hk/ppp_en/11_useful_info/facts.html (accessed 9 July 2019).

Hong Kong Police Force (2018b), Environmental Scan Report 2018, Government Logistics Department, Hong Kong.

Hong Kong Police Force (2018c), Management Information Pack, Government Logistics Department, Hong Kong.

Hong Kong Police Force (2019a), Strategic Directions 2019-2021, Government Logistics Department, Hong Kong.

Hong Kong Police Force (2019b), Strategic Action Plan, Hong Kong Police Force, Hong Kong.

Hong Kong Police Force (2020), "Chapter 68 Force strategic management”, Force Procedures Manual, Hong Kong Police Force, Hong Kong.

Inayatullah, S. (2007), "The study of the future", in Inayatullah, S. (Ed.), Questioning the Future: Methods and Tools for Organizational and Societal Transformation, Tamkang University Press, Tamsui, pp. 6-20.

Inayatullah, S. (2008), "Six pillars: futures thinking for transforming”, Foresight, Vol. 10 No. 1, pp. 4-28.

Legatum Institute (2019), "The Legatum Prosperity Index 2019 (Safety \& Security)”, available at: https://www.police.gov.hk/info/doc/Legatum_Prosperity_Index_e.pdf (accessed 18 May 2020).

Maslow, A.H. (1943), "A theory of human motivation”, Psychological Review, Vol. 50 No. 4, pp. 370-396.

McClelland, D.C. (2010), The Achieving Society, Martino Fine Books, New York, NY.

McRee, C.K. (2018), "Managerial perceptions of employee motivation", Theses and Dissertations, Pepperdine Digital Commons, available at: https:/digitalcommons.pepperdine.edu/cgi/ viewcontent.cgi?article $=2000 \&$ context $=$ etd (accessed 31 August 2020).

Mintzberg, H. (1987), “Crafting strategy”, Harvard Business Review, Vol. 65 No. 4, pp. 66-75.

Mintzberg, H. (1994), "The fall and rise of strategic planning”, Harvard Business Review, Vol. 72 No. 1, pp. 107-114.

Nicholls, J. (1994), “The 'heart, head and hands' of transforming leadership", Leadership and Organization Development Journal, Vol. 15 No. 6, pp. 8-15.

Paton, C. (2018), "Strategic agility", Strategy Magazine, Vol. 1, pp. 15-18.

Ryan, R.M. and Deci, E.L. (2008), "Self-determination theory and the role of basic psychological needs in personality and the organization of behaviour", in John, O.P., Robins, R.W. and Pervin, L.A. (Eds.), Handbook of Personality Theory and Research, The Guilford Press, New York, NY, pp. 654-678.

Senge, P.M. (1990), “The leader's new work: building learning organizations”, MIT Sloan Management Review, Vol. 32 No. 1, pp. 7-23.

Senge, P.M. (2003), "Taking personal change seriously: the impact of organizational learning on management practice", Academy of Management Perspectives, Vol. 17 No. 2, pp. 47-50.

Woodling, G. and Jones, W. (2018), “Incorporating 'futures' foresight into the process of strategic planning”, Strategy Magazine, Vol. 1, pp. 4-7.

Yu, E. (1997), "Introducing 3H Framework", working paper, City University of Hong Kong, Hong Kong.

Yu, E. (2019), Seminar day 1: Visions for the future: theoretical perspectives on management, lecture notes, SBPD7004, University of Wales - Trinity Saint David, 8 June 2019.

Zhao, J.S., Thurman, Q.C. and Ling, R. (2008), "An examination of strategic planning in American law enforcement agencies: a national study", Police Quarterly, Vol. 11 No. 1, pp. 3-26.

\section{About the authors}

Hoi-yan Cheung is a serving police officer with 24 years of service with the Hong Kong Police Force. She currently holds the rank of Senior Superintendent of Police. She is also a doctoral student in Business
Strategic
planning in
Hong Kong
Police Force

257 
Administration at University of Wales Trinity Saint David, UK. Her research interest is strategic management in the public sector. Hoi-yan Cheung is the corresponding author and can be contacted at: hoiyan@alumni.cuhk.net

Eddie $\mathrm{Yu}, \mathrm{PhD}$, after retired from City University of Hong Kong, he was appointed as Adjunct Professor of Hong Kong Management Association and teaching courses for Georgetown University, University of Cologne and University of Wales TSD. Dr. Yu is the founding President of the International Quality Service Management Association.

For instructions on how to order reprints of this article, please visit our website: www.emeraldgrouppublishing.com/licensing/reprints.htm Or contact us for further details: permissions@emeraldinsight.com 